\title{
Investigation of Bone Mineral Density Levels of Adult Individuals in Different Professional Groups, Sedentary People, and the Same Age Group Athletes
}

\author{
Kürşat Hazar ${ }^{1}$, Recep Gürsoy², Neşat Çullu ${ }^{3}$ \\ ${ }^{1}$ School of Physical Education and Sport, Osmaniye Korkut Ata University, Osmaniye, Turkey \\ ${ }^{2}$ Faculty of Sport Sciences, Department of Coaching Education, Muğla Sitki Koçman University, Muğla, Turkey \\ ${ }^{3}$ Faculty of Medicine, Department of Internal Medicine, Radiology Muğla Sitki Koçman University, Muğla, Turkey \\ Email: *recepgursoy@mu.edu.tr
}

How to cite this paper: Hazar, K., Gürsoy, R., \& Çullu, N. (2020). Investigation of Bone Mineral Density Levels of Adult Individuals in Different Professional Groups, Sedentary People, and the Same Age Group Athletes. Advances in Physical Education, 10, 251-261.

https://doi.org/10.4236/ape.2020.103021

Received: April 28, 2020

Accepted: August 3, 2020

Published: August 6, 2020

Copyright ( 2020 by author(s) and Scientific Research Publishing Inc. This work is licensed under the Creative Commons Attribution International License (CC BY 4.0).

http://creativecommons.org/licenses/by/4.0/

\begin{abstract}
This study was carried out to determine how and to what extent the physical activity of sedentary and sportive life affects the bone mineral density (BMD) of individuals in different occupational groups (barbers, industrial workers, drivers, people leading sedentary lives, and athletes), which concern a large part of the society. Barbers, industrial workers, drivers, sedentary people, and athletes working in different occupational groups were included in the study. Femur and forearm (ulna-radius) BMD measurements of 47 individuals were conducted, including 7 drivers and 10 participants from each other professional group. BMD total femur values of the athletes are 1.2664, of industrial workers, is 1.1876 , of drivers, is 1.0544 , of hairdressers, is 1.0208 , and values of sedentary people are found as 1.0080. In the total of BMD Ulna Radius, the values of industry employees are found as 0.685 , of athletes as 668 , of barbers as 582 , and of sedentary people are found to be 0.449 . There was a significant difference between the mean BMD values of industrial workers and the barbers, and sedentary people, in favor of industrial workers $(p<0.05)$. When multiple analyzes between groups were examined; it was found that there was a significant difference between only the average values of sedentary people and industrial workers and athletes in forearm BMD value averages $(p<0.05)$. The values of athletes and industrial workers are higher than those of sedentary people. While BMD of individuals in five different occupational groups was found to have a positive effect on BMD, especially with occupational groups requiring physical activation, it was found that sedentary life did not have a positive effect on BMD.
\end{abstract}




\section{Keywords}

Bone Mineral Density, Profession, Sportsman, Sedentary

\section{Introduction}

In advance, people used to use physical strength to carry out their occupation and to continue their lives. Nowadays, body power has been replaced by machines and technological tools that proceed at an extraordinary speed. In addition to facilitating human life, these devices have brought many problems along. One of the most important problems is bone mass loss due to inactivity, osteoporosis, and fractures (Vuori, 2004).

Osteoporosis is one of the most important diseases in the present day due to the sedentary lifestyle. Osteoporosis creates a major health problem with its low bone density and microarchitecture of the bone, causes an increase in the risk of bone tissue disruption and fracture (Christodoulou \& Copeer, 2003). It is known that physical activity, some occupational activities that require strength and sports activities are effective on bone mineral density and other systems (Akgün, 1989). It is known that high and effective loading activities in athletes improve bone mineral density (BMD). It has been reported that the excessive mechanical load that athletes are exposed to at a young age positively affects BMD by leaving effects on bone formation (Markou et al., 2010).

In young adults, bone mineral content (BMC) and $\mathrm{BMD}$ values were found to be higher in strength and strength-trained athletes, but less effective in endurance activities such as long-distance running and swimming. BMC and BMD are significantly higher in middle-aged and old male athletes, especially in trabecular bone regions (Suominen, 1993).

Exercise and mechanical loads caused by different physical activities contribute to bone reconstruction, preservation of existing bone mass and formation of peak bone mass (Nas \& Çevik, 2000). Exercise has a great role in the prevention of osteoporosis. While loads other than daily living activities increase bone mineral density levels in long bones. long-term inactive life has been reported to cause osteoporosis (Tüzün, 2003). This article aims to evaluate how and to what extent different occupational groups, different lifestyles, physical activities, and sport life affect bone mineral density, which is regarding the majority of society.

\section{Material and Method}

\subsection{Study Population}

The present study is a prospective study. Barbers, industrial workers, drivers, sedentary people and athletes living in the Muğla region and working in different occupational groups were included in the study. Volunteer individuals aged between 40 - 50 years were included in this study. BMD measurements of 47 individuals including 7 drivers and 10 participants in each occupational group 
were performed. In addition to sedentary individuals, individuals who used hands and wrists in different occupational groups, and athletes who were active in various branches in past years and who are still engaged in daily physical activities, were included in the study. This study was carried out by Muğla Sitki Koçman University Scientific Research Projects Coordination Unit between 2017-2018 with the code number $17 / 162$. In this research, conducted within the scope of BAP, budget opportunities were taken into consideration in determining the number of subjects. Also, all the individuals in the research groups were confirmed from the registered occupational chambers where they had at least 10 years of profession. In the study, bone mineral density measurements were limited with the measurement of DEXA (Dual-energy X-ray absorptiometry) device in Muğla Sitki Koçman University Training and Research Hospital.

\subsection{Data Collection}

The ethics committee approval of this study was obtained from the ethics committee of our university. Subjects were enlightened about the study and the participation of individuals on a voluntary basis was ensured. In order to determine the demographic characteristics of the participants, a personal information form was prepared and the necessary data were obtained. Height, weight and BMD measurements of the participants were conducted. Height and weight measurements of the individuals were made by the technician in charge and added to the system. The height measurements of the participants were obtained with Holtain Limited height meter with a sensitivity of $0.01 \mathrm{~cm}$ and body weight with Angel electronic scale with a sensitivity of $0.1 \mathrm{~kg}$.

In this study, bone mineral density measurements were made with DEXA measurement (STRATOS DR with DMS brand serial number TAEK 15274, license number 4959-001-KB-23-L). It was ensured that the participants were wearing appropriate clothing by taking care not to have any metal objects on them during the measurements. During the measurement, each participant was carefully placed on the DEXA table and the screening process was completed.

\subsection{Statistical Analysis}

SPSS v24.00 statistical package program was used for data analysis. Arithmetic average, standard deviation, minimum and maximum values for continuous variables were given together. Normality distribution of the data was performed by Kolmogorov-Smirnov and Shapiro-Wilk tests. Parametric tests were used for data showing normal distribution. While variance analysis (ANOVA) test was used to compare the values of occupational groups, multiple comparisons were made with the Tukey test. The significance level was taken as $p<0.05$ in parametric tests.

\section{Results}

Descriptive findings of all groups included in the study are shown in Table 1. 
Table 1. Descriptive findings of the groups.

\begin{tabular}{|c|c|c|c|c|c|c|}
\hline \multicolumn{2}{|c|}{ Occupation } & $\mathrm{N}$ & Minimum & Maximum & $\bar{X}$ & Std. D. \\
\hline \multirow{4}{*}{ Barbers } & Age (year) & 10 & 40 & 50 & 43.200 & 3.882 \\
\hline & Height $(\mathrm{cm})$ & 10 & 164 & 190 & 172.300 & 6.800 \\
\hline & Weight $(\mathrm{kg})$ & 10 & 62 & 103 & 81.900 & 12.914 \\
\hline & Placement Year & 10 & 19 & 35 & 28.300 & 4.900 \\
\hline \multirow{4}{*}{ Industrial Workers } & Age (year) & 10 & 40 & 49 & 45.200 & 3.155 \\
\hline & Height $(\mathrm{cm})$ & 10 & 157 & 179 & 168.600 & 6.222 \\
\hline & Weight (kg) & 10 & 60 & 118 & 83.800 & 17.937 \\
\hline & Placement Year & 10 & 20 & 35 & 27.500 & 5.986 \\
\hline \multirow{4}{*}{ Sedentary People } & Age (year) & 10 & 40 & 49 & 43.700 & 3.860 \\
\hline & Height $(\mathrm{cm})$ & 10 & 156 & 190 & 170.700 & 9.844 \\
\hline & Weight $(\mathrm{kg})$ & 10 & 67 & 103 & 82.000 & 12.481 \\
\hline & Placement Year & 10 & 12 & 30 & 21.400 & 4.926 \\
\hline \multirow{4}{*}{ Athletes } & Age (year) & 10 & 42 & 50 & 45.900 & 3.381 \\
\hline & Height $(\mathrm{cm})$ & 10 & 162 & 193 & 178.800 & 9.102 \\
\hline & Weight $(\mathrm{kg})$ & 10 & 61 & 102 & 88.200 & 13.653 \\
\hline & Placement Year & 10 & 16 & 30 & 21.900 & 4.175 \\
\hline \multirow{4}{*}{ Drivers } & Age (year) & 7 & 40 & 50 & 43.286 & 4.716 \\
\hline & Height $(\mathrm{cm})$ & 7 & 160 & 187 & 167.714 & 8.845 \\
\hline & Weight $(\mathrm{kg})$ & 7 & 64 & 110 & 85.000 & 17.597 \\
\hline & Placement Year & 7 & 15 & 25 & 19.714 & 4.271 \\
\hline
\end{tabular}

The femoral mineral density measurement findings of all groups included in the study are given in Table 2.

Anova table on comparison of femoral bone mineral density values findings included in the study are given in Table 3.

According to the variance analysis test for the comparison of femoral bone mineral density values, a significant difference was found between the groups $\left[\mathrm{F}_{(\mathrm{df} 4)}=0.785 p<0.000\right]$.

Multiple comparison of femur bone mineral density of different occupationgroups findings of all groups included in the study are given in Table 4.

When multiple analyzes were performed among groups, femur BMD values of athletes and industrial workers were higher than those of barbers $(p<0.05, p<$ $0.01)$. There was a significant difference between the average BMD values of industrial workers, barbers, and sedentary people in favor of industrial workers ( $p$ $<0.05)$. When the table is examined, there is no significant difference between the average BMD values of industrial workers, athletes, and drivers $(p>0.05)$.

The femur BMD values of industrial workers and athletes were significantly different from those of sedentary people $(p<0.05, p<0.01)$. The femur BMD values of the athletes were significantly different from the values of barbers, sedentary people, and drivers $(p<0.01)$. When the average BMD values of the athletes and the values of the drivers were examined, there was a significant difference in favor of the athletes $(p<0.01)$. 
Table 2. Descriptive findings related to femoral bone mineral density of subjects in different occupational groups.

\begin{tabular}{ccccccc}
\hline Variables & Occupations & $\mathrm{N}$ & $\bar{X}$ & Std. D. & Min & Max \\
\hline & Barber & 10 & 1.0208 & 0.06918 & 0.93 & 1.11 \\
& Industrial Worker & 10 & 1.1876 & 0.09617 & 1.00 & 1.30 \\
Femur KMY $\left(\mathrm{g} / \mathrm{cm}^{2}\right)$ & Sedentary People & 10 & 1.0080 & 0.09163 & 0.87 & 1.15 \\
& Athletes & 10 & 1.2664 & 0.19042 & 1.10 & 1.63 \\
& Drivers & 7 & 1.0544 & 0.12477 & 0.80 & 1.17 \\
\hline
\end{tabular}

Table 3. Anova table on comparison of femoral bone mineral density values.

\begin{tabular}{ccccccc}
\hline \multicolumn{2}{c}{ Variables } & Sum of squares & Std. D. & Average of Squares & F & $p$ \\
\hline \multirow{2}{*}{$\begin{array}{c}\text { Femur KMY } \\
\left(\mathrm{g} / \mathrm{cm}^{2}\right)\end{array}$} & Between Groups & 0.461 & 4 & 0.115 & & \\
& In-group & 0.563 & 38 & 0.015 & 7.785 & $0.000^{\star *}$ \\
& Total & 1.024 & 42 & & & \\
\hline
\end{tabular}

${ }^{* *}: p<0.01$.

Table 4. Multiple comparison of femur bone mineral density of different occupation groups.

\begin{tabular}{|c|c|c|c|c|c|}
\hline Variables & (I) Occupation & (j) Occupation & $\begin{array}{l}\text { Difference between } \\
\text { averages (I-J) }\end{array}$ & Std. D. & $p$ \\
\hline \multirow{20}{*}{$\begin{array}{c}\text { Femur BMD } \\
\quad\left(\mathrm{g} / \mathrm{cm}^{2}\right)\end{array}$} & \multirow{4}{*}{ Barbers } & Industrial Workers & -0.167 & 0.057 & $0.045^{\star}$ \\
\hline & & Sedentary People & 0.013 & 0.057 & 0.999 \\
\hline & & Athletes & -0.246 & 0.057 & $0.001^{\star *}$ \\
\hline & & Drives & -0.034 & 0.061 & 0.981 \\
\hline & \multirow{4}{*}{$\begin{array}{l}\text { Industrial } \\
\text { Workers }\end{array}$} & Barbers & 0.167 & 0.057 & $0.045^{\star}$ \\
\hline & & Sedentary People & 0.180 & 0.057 & $0.026^{*}$ \\
\hline & & Athletes & -0.079 & 0.057 & 0.647 \\
\hline & & Drives & 0.133 & 0.061 & 0.213 \\
\hline & \multirow{4}{*}{$\begin{array}{c}\text { Sedentary } \\
\text { People }\end{array}$} & Barbers & -0.013 & 0.057 & 0.999 \\
\hline & & Industrial Workers & -0.180 & 0.057 & $0.026^{*}$ \\
\hline & & Athletes & -0.258 & 0.057 & $0.001^{\star *}$ \\
\hline & & Drives & -0.046 & 0.061 & 0.941 \\
\hline & \multirow{4}{*}{ Athletes } & Barbers & 0.246 & 0.057 & $0.001^{\star *}$ \\
\hline & & Industrial Workers & 0.079 & 0.057 & 0.647 \\
\hline & & Sedentary People & 0.258 & 0.057 & $0.001^{\star *}$ \\
\hline & & Drives & 0.212 & 0.061 & $0.011^{*}$ \\
\hline & \multirow{4}{*}{ Drives } & Barbers & 0.034 & 0.061 & 0.981 \\
\hline & & Industrial Workers & -0.133 & 0.061 & 0.213 \\
\hline & & Sedentary People & 0.046 & 0.061 & 0.941 \\
\hline & & Athletes & -0.212 & 0.061 & $0.011^{\star}$ \\
\hline
\end{tabular}

${ }^{*}: p<0.05,{ }^{* *}: p<0.01$.

Forearm (ulna-radius) mineral density measurements of all groups included in the study are given in Table 5.

Anova table on comparison of forearm Ulna Radius bone mineral density values findings included in the study are given in Table 6. 
According to the results of the variance analysis, a significant difference was found between the groups $\left[\mathrm{F}_{(\mathrm{df} 4)}=2.757, p<0.042\right]$.

Multiple Comparison of Forearm Bone Mineral Density of Different Occupation Groups findings of all groups included in the study are given in Table 7.

Table 5. Descriptive statistics of forearm (ulna-radius) bone mineral density of individuals from different occupational groups.

\begin{tabular}{ccccccc}
\hline Variables & Occupations & $\mathrm{N}$ & $\bar{X}$ & Std. D. & Min & Max \\
\hline \multirow{2}{*}{$\begin{array}{c}\text { Forearm BMD } \\
\left(\mathrm{g} / \mathrm{cm}^{2}\right)\end{array}$} & Barbers & 10 & 0.582 & 0.0431 & 0.52 & 0.67 \\
& Sedentary People & 10 & 0.449 & 0.3665 & -0.52 & 0.65 \\
& Athletes & 10 & 0.668 & 0.0203 & 0.64 & 0.70 \\
& Driver & 7 & 0.637 & 0.0466 & 0.56 & 0.69 \\
\hline
\end{tabular}

Table 6. ANOVA table on comparison of forearm ulna radius bone mineral density values.

\begin{tabular}{ccccccc}
\hline \multicolumn{2}{c}{ Variables } & Sum of squares & Std. D. & Average of Squares & F & $p$ \\
\hline \multirow{2}{*}{ Forearm } & Between Groups & 0.325 & 4 & 0.081 & & \\
BMD $\left(\mathrm{g} / \mathrm{cm}^{2}\right)$ & In-group & 1.121 & 38 & 0.030 & 2.757 & 0.042 \\
& Total & 1.447 & 42 & & & \\
\hline
\end{tabular}

${ }^{*}: p<0.05,{ }^{* *}: p<0.01$.

Table 7. Multiple comparison of forearm bone mineral density of different occupation groups.

\begin{tabular}{|c|c|c|c|c|c|}
\hline Variables & (I) Occupation & (J) Occupation & $\begin{array}{l}\text { Difference between } \\
\text { averages (I-J) }\end{array}$ & Std. D. & $p$ \\
\hline \multirow{20}{*}{$\begin{array}{l}\text { Forearm } \\
\text { BMD } \\
\left(\mathrm{g} / \mathrm{cm}^{2}\right)\end{array}$} & \multirow{4}{*}{ Barbers } & Industrial Workers & -0.103 & 0.081 & 0.707 \\
\hline & & Sedentary People & 0.133 & 0.081 & 0.478 \\
\hline & & Athletes & -0.086 & 0.081 & 0.825 \\
\hline & & Drives & -0.055 & 0.087 & 0.968 \\
\hline & \multirow{4}{*}{$\begin{array}{l}\text { Industrial } \\
\text { Workers }\end{array}$} & Barbers & 0.103 & 0.081 & 0.707 \\
\hline & & Sedentary People & 0.237 & 0.081 & $0.043^{*}$ \\
\hline & & Athletes & 0.017 & 0.081 & 1.000 \\
\hline & & Drives & 0.048 & 0.087 & 0.980 \\
\hline & \multirow{4}{*}{$\begin{array}{l}\text { Sedentary } \\
\text { People }\end{array}$} & Barbers & -0.133 & 0.081 & 0.478 \\
\hline & & Industrial Workers & -0.237 & 0.081 & $0.043^{*}$ \\
\hline & & Athletes & 0.235 & 0.081 & $0.047^{\star}$ \\
\hline & & Drives & -0.188 & 0.087 & 0.211 \\
\hline & \multirow{4}{*}{ Athletes } & Barbers & 0.086 & 0.081 & 0.825 \\
\hline & & Industrial Workers & -0.017 & 0.081 & 1.000 \\
\hline & & Sedentary People & 0.235 & 0.081 & $0.047^{\star}$ \\
\hline & & Drives & 0.031 & 0.087 & 0.996 \\
\hline & \multirow{4}{*}{ Drives } & Barbers & 0.055 & 0.087 & 0.968 \\
\hline & & Industrial Workers & -0.048 & 0.087 & 0.980 \\
\hline & & Sedentary People & 0.188 & 0.087 & 0.211 \\
\hline & & Athletes & -0.031 & 0.087 & 0.996 \\
\hline
\end{tabular}

${ }^{*}: p<0.05,{ }^{* *}: p<0.01$. 
When multiple analyzes between groups are examined, there is a significant difference only between sedentary people's values and industrial workers athletes' average values in BMD average values $(p<0.05)$. The values of athletes and industrial workers are higher than those of sedentary people. There was no significant difference between the average values of the other groups.

\section{Discussion}

In this study, by analyzing the differences between the bone mineral density of different occupational groups (barbers, industrial workers, drivers, and athletes) and sedentary individuals between the ages of 40 - 50, their effects on bone mineral density were investigated. Total femur BMD was found to be the highest value in the athletes while it was 1.2664; industrial workers $1.1876 ; 1.0544$ in drivers; 1.0208 in barbers; the lowest value was found 1.0080 in sedentary people. As a result, statistically significant differences were found between the groups. $\left[\mathrm{F}_{(\mathrm{df} 4)}=7.785\right](p<0.001)$. According to the multiple comparison test results, there was a significant difference between the total femur BMD of the groups in favor of athletes and industrial workers $(p<0.05, p<0.01)$; there was no difference between the other groups $(p>0.05)$.

Welsh and Rutherford, who evaluated paced walks and jump rope exercises in sedentary men for one year, also found a significant increase in femoral neck and trochanter (BMD) (Welsh \& Rutherford, 1996). Besides, in a study conducted on 44 elderly runners over 65 years old, significantly higher total body BMD was found compared to sedentary subjects. It has been reported that submaximal exercises performed 45 - 50 minutes 3 - 4 times a week are effective on the lumbar spine and femur BMD (Platen, 1995). Hamilton et al. reported that high-impact exercises were the most significant impacts of bone mass increase (Hamilton et al., 2010). In healthy adult individuals, the primary purpose should be to reduce or preserve bone loss due to natural aging. In another study, lumbar and femur measurements were performed to determine the effect of different load types on BMD and BMD of those with high-intensity activity was found to be significantly different from those with low-intensity activity. Also, it has been reported that stresses on different parts of the skeleton affect BMD (Grimston et al., 1993).

According to the findings of the study, it was observed that long-distance bus drivers, barbers, and sedentary individuals lead a more inactive life in terms of occupational characteristics; but athletes and industrial workers have a more active lifestyle. Depending on these studies, it can be said that the exercises planned to be done for the prevention of osteoporosis should be resistance exercises that create a high impact effect. In the study, 40 - 50 age group and middle-age individuals in different occupational groups formed the experimental group. Their lifestyles and daily physical activity levels differ. It is thought that both peak bone mass (PBM) and high-intensity resistance exercises on different body parts have effects on BMD. 
When the total BMD of the forearms of the individuals in different occupational groups was examined, the highest value was found to be 0.685 for industrial workers, 0.666 for athletes, 0.637 for bus drivers, 0.582 for barbers, and the lowest values was found as 0.449 for sedentary people. According to the variance analysis test, there was a statistically significant difference between the groups $\left[\mathrm{F}_{(\mathrm{df} 4)}=2.757, p<0.042\right]$. According to multiple comparison test results, forearm total values were found to be significantly different from sedentary people in favor of athletes and industrial workers $(p<0.05)$; there was no significant difference between the other groups.

Mechanical loads are reported to be an important factor in determining bone mass, structure, and strength (Peterson et al., 1991). Physical activity has been shown to positively affect DKK in humans (Conroy et al., 1993). At the same time, regular exercise is very important in both adolescent and young adults to obtain and maintain peak bone mass (Halioua \& Anderson, 1989). To provide beneficial effects of exercise on both regional and total bone mass, the bone must be a weight loader (Fiore et al., 1996). The response of the bone to mechanical loading depends on the bone site on which the load overlaps and the type of exercise (Madsen et al. in their research between sports branches that require weight loading and sedentary, in the branches that require weight loading athletes' lumbar, femoral neck and total body values were found to be more significant than sedentary in the same age group (Madsen et al., 1995).

In another study to investigate the effect of different exercise types on BMD, comparisons of lumber area, femoral head, and forearm BMD of a group of middle and long-distance runners, a group of tennis players and a group of sedentary women aged 40 - 65 years, a group of tennis players and a group of sedentary females was conducted with DEXA measurement device, and tennis players' BMD values were higher than the runners, and runners' BMD values were found to be higher than those of sedentary group (Yabanci, 1999).

In a similar study, 18 - 25-year-old (70 males and 40 females) volunteer athletes (Wrestling, Football, Volleyball, Handball, Basketball, and Athletics), and a sedentary group of 20 people (10 males and 10 females) were included in the study. After the lumbar, vertebral femur and forearm measurements, the athletes' values were higher than the sedentary group (Sivrikaya, 2000).

To determine the intensity of different exercise types and load types on the values; in a study of 15 runners, cyclist and swimmer women and sedentary women, BMD of the total body, lumbar and femoral neck of the participants was measured and the total values of the runners were found to be higher than the swimmers and sedentary women. Since running activities put more burden on the bones, BMDs in specific parts have been reported to be higher than other groups (Duncan et al., 2002). Although the forearm total values of the longdistance bus drivers and barbers in the study group were close to industry workers and athletes, it was not found to be statistically significant $(p>0.05)$. It is assumed that the reason for this is that the intensity of the hand and arm activities performed by bus drivers and barbers due to their professional characteristics 
and the resistance to which the forearm is exposed is lower than that of industrial workers and athletes.

The forearm values of athletes and industrial workers were significantly different from those of sedentary people $(p<0.05)$. This difference is thought to be since sedentary individuals are not able to lead an active life and do not provide sufficient resistance to hand and arm use in daily living activities.

As a result; In this study, BMD of individuals in five different occupational groups (barbers, industrial workers, sedentary, drivers, and athletes) were examined and it was seen that while occupation groups especially requiring physical activity and sporty lifestyle has a positive effect on BMD, sedentary lifestyle do not have positive effect on BMD.

\section{Disclosure}

This study has been supported by the Coordination Unit of the Scientific Research Projects of Mugla Sitki Koçman University with the code number 17/162. In addition, this study was produced from the author's thesis titled The Investigation of Bone Mineral Density Levels of Adult Individuals, Sedentary and Athletes in Different Age Groups, 2019. The authors of this article did not specify any other related relationships that could be perceived as a real or open conflict of interest. No potential conflicts of interest relevant to this article exist. The authors alone are responsible for the content and writing of the manuscript.

\section{Perspective}

In this study, bone mineral density (BMD) levels of people in different professions were investigated. As a result of the research, it is seen that different occupational groups and sportive life that require physical activity affect the BMD levels of people positively; It was determined that those who lead sedentary life were negatively affected. Therefore, it is recommended that those who lead sedentary life to participate in physical activities.

\section{Acknowledgements}

This study was financed by the Muğla Sitki Koçman University Scientific Research Projects (SRP) unit. All of the authors declare no interest. In this study, we would like to thank Muğla Sitki Koçman University SRP unit and the Research Hospital Department of Radiology staff.

\section{Conflicts of Interest}

The authors declare no conflicts of interest regarding the publication of this paper.

\section{References}

Akgün, N. (1989). Exercise Physiology. Publication of the Prime Ministry General Directorate of Youth and Sports. Ankara 2(3). 
Christodoulou, C., \& Cooper, C. (2003). What Is Osteoporosis. Postgraduate Medical Journal, 79, 133-138. https://doi.org/10.1136/pmj.79.929.133

Conroy, B. P., Kraemer, W. J., \& Maresh, C. M. (1993). Bone Mineral Density in Elite Junior Olympic Weightlifters. Medicine \& Science in Sports \& Exercise, 25, 1103-1109. https://doi.org/10.1249/00005768-199310000-00004

Duncan, C. S., Blimkie, C. J., Cowell, C. T., Burke, S. T., Briody, J. N., \& Howman, G. R. (2002). Bone Mineral Density in Adolescent Female Athletes: Relationship to Exercise Type and Muscle Strength. Medicine \& Science in Sports \& Exerciseise, 34, 286-294. https://doi.org/10.1097/00005768-200202000-00017

Fiore, C. E., Dieli, M., Vintaloro, G., Gibilaro, M., Glicone, G., \& Cottini, E. (1996). Body Composition and Bone Mineral Density in Competitive Athletes in Different Sports. International Journal of Tissue Reactions, 4, 121-124.

Grimston, S. K., Tanguay, K. E., Gundberg, C. M., \& Hanley, D. A. (1993). The Calciotropic Hormone Response to Changes in Serum Calcium during Exercise in Female Long Distance Runners. The Journal of Clinical Endocrinology \& Metabolism, 76, 867-872. https://doi.org/10.1210/jcem.76.4.8473398

Halioua, L., \& Anderson, J. (1989). Lifetime Calcium Intake and Physical Activity Habits Independent and Combined Effects on the Radial Bone of Healthy Premenopausal Caucasian Women. American Journal of Clinical Nutrition, 49, 534-541. https://doi.org/10.1093/ajcn/49.3.534

Hamilton, C. J., Swan, V. J., \& Jamal, S. A. (2010). The Effects of Exercise and Physical Activity Participation on Bone Mass and Geometry in Postmenopausal Women: A Systematic Review of pQCT Studies. Osteoporosis International, 21, 11-23. https://doi.org/10.1007/s00198-009-0967-1

Madsen, K. L., Adams, W. C., \& Van Loan, M. D. (1995). Effects of Physical Activity, Body Weight and Composition, and Muscular Strength on Bone Density in Young Women. Medicine \& Science in Sports \& Exercise, 30, 114-120. https://doi.org/10.1097/00005768-199801000-00016

Markou, K. B., Theodoropoulou, A., Tsekouras, A., Vagenakis, A. G., \& Georgopoulos, N. A. (2010). Bone Acquisition during Adolescence in Athletes. Annals of the New York Academy of Sciences, 1205, 12-16. https://doi.org/10.1111/j.1749-6632.2010.05675.x

Nas, K., \& Çevik, R. (2000). Risk Factors in Osteoporosis. Diagnosis and Treatment in Osteoporosis, 70-90.

Peterson, S. E., Peterson, M. D., Raymond, G., Gilligan, C., Checovich, M. M., \& Smith, E. L. (1991). Muscular Strength and Bone Density with Weight Training in Middle-Aged Women. Medicine \& Science in Sports \& Exercise, 23, 499-504. https://doi.org/10.1249/00005768-199104000-00017

Platen, P. (1995). Mobilitaet, Fitness und Osteoporoseentstehung. Körperliche Belastung und Knochenmasse. Deutsche Zeitschrift für Sportmedizin, 46, 48-56.

Sivrikaya, A. H. (2000). Effects of Different Sports Branches on Bone Mineral Density in Male and Female Athletes. Erzurum: Atatürk University, Institute of Health Sciences.

Suominen, H. (1993). Bone Mineral Density and Long Term Exercise. Sports Medicine, 16, 316-330. https://doi.org/10.2165/00007256-199316050-00003

Tüzün, F. (2003). Overview of Osteoporosis (pp. 9-10). Istanbul: Osteoperosis and Bone Quality in Bone Joint Decade.

Vuori, I. (2004). Physical Inactivity Is a Cause and Physical Activity Is a Remedy for Major Public Health Problems. Kinesiology, 36, 123-153. 
Welsh, L., \& Rutherford, O. M. (1996). Hip Bone Mineral Density Is Improved by High-Impact Aerobic Exercise in Postmenopausal Women and Men over 50 Years. European Journal of Applied Physiology and Occupational Physiology, 74, 511-517. https://doi.org/10.1007/BF02376766

Yabanci, N. (1999). The Effect of Physical Activity Level and Nutritional Status on Bone Mineral Density and Body Composition in Adolescents. Ankara: Hacettepe University, Institute of Health Sciences. 